Ensino, Saúde e Ambiente - v. 14 n. esp. (2021): Dossiê Paulo Freire para além dos 100 anos:

construir utopias, transformar a realidade, p. 288-300.

Lutas sociais e educação popular

ENSINO, SAÚDE E AMBIENTE

\title{
Por que Paulo Freire comprometeu-se com a educação de jovens e adultos e não de crianças?
}

\author{
Why did Paulo Freire commit himself to the literacy of young people \\ and adults instead of children?
}

Walter Omar Kohan ${ }^{1}$

Palavras-chave:

Paulo Freire; infância; alfabetização; pedagogia da pergunta; tempo
RESUMO: O texto considera a pergunta "Por que Paulo Freire comprometeu-se com a educação de jovens e adultos e não de crianças?" não com a pretensão de respondê-la de forma terminante, mas de dar vida a uma pedagogia da pergunta. Para isso, o texto aborda diversos aspectos da curiosidade em Paulo Freire bem como sua relação com a infância cronológica e o tempo de infância. Repassamos sua intervenção no $3^{\circ}$ Congresso de Leitura em Campinas (COLE) e sua correspondência com a prima/sobrinha Nathercinha. Finalmente, lançamos alguma hipótese sobre a pergunta que nos ocupa a partir de dois elementos essenciais em sua vida educadora: a curiosidade e o compromisso com as e os excluídos.

\section{Keywords:}

Paulo Freire; childhood literacy; pedagogy of the question; time
ABSTRACT: The text considers the question "Why did Paulo Freire commit himself to the education of young people and adults and not of children?" not with the intention of answering it definitively, but of giving life to a pedagogy of the question. For this, the text addresses several aspects of the notion of curiosity in Paulo Freire as well as his relationship with chronological childhood and the time of childhood. We review his intervention at the 3rd Reading Congress in Campinas (COLE) and his correspondence with his cousin/niece Nathercinha. Finally, we launch a hypothesis about the question that concerns us based on two essential elements in his educational life: curiosity and commitment to the excluded.

O título deste artigo é uma pergunta: Por que Paulo Freire comprometeu-se com a educação de jovens e adultos e não de crianças? Ela expressa uma curiosidade sobre o Patrono da Educação Brasileira. Escrever sobre essa pergunta tem a pretensão de provocar o

\footnotetext{
${ }^{1}$ Professor Titular da UERJ; Pesquisador do CNPq e da FAPERJ; Coordenador do CAPES/PrInt "Filosofia na Infância da vida Escolar”. Email: wokohan@gmail.com. ORCID: https://orcid.org/0000-0002-2263-9732
} 
Ensino, Saúde e Ambiente - v. 14 n. esp. (2021): Dossiê Paulo Freire para além dos 100 anos: construir utopias, transformar a realidade, p. 288-300.

\section{Lutas sociais e educação popular}

pensamento antes de que propriamente respondê-la. Mesmo que tendamos a pensar que as perguntas precisam ser respondidas da forma mais segura e definitiva possível, o sentido principal deste texto não é responder, de forma acabada, a pergunta que nos colocamos. Dito de outra forma, vamos tentar responder a pergunta do título, mas sem respondê-la completamente, de uma forma que acabe a inquietação que movimenta essa pergunta. Ainda com outras palavras, vamos respondê-la de uma maneira em que a pergunta, mesmo respondida, mereça ser mantida, pensada, considerada. E que também dê lugar a outras perguntas.

Seremos ainda mais concretos e explícitos: Nossa pergunta começa por "Por que" e as perguntas que começam por "por que" chamam respostas de tipo muito diverso: razões, causas, motivos, fundamentos. Quando o "por que” está dirigido a alguém - e mais ainda alguém que já não está vivo -, como neste caso, uma resposta que pretendesse responder a nossa pergunta de forma acabada exigiria uma profunda pesquisa biográfica, histórica, documental. Mas não é o nosso caso: queremos estabelecer uma outra relação com a pergunta; não pretendemos responder por que, de fato, Paulo Freire ocupou-se de uma faixa etária e não de outra, mas o que nos pode fazer pensar que ela tenha se ocupado da educação de jovens e adultos sendo que ele também outorgava à infância uma importância fundamental. Os porquês de uma vida são tão infinitos quanto as questões que essa vida pode nos fazer pensar.

A questão que nos ocupa não é sem importância. A relação que estabelecemos com as perguntas cobra ainda mais relevância tratando-se do autor (junto com o chileno Antonio Faundez) do livro Por uma pedagogia da pergunta. Nesse livro, os dois amigos insistem sobre o valor fundamental, educativo e político, do perguntar: com efeito, aprender a perguntar é considerado um ato profundamente democrático (FREIRE; FAUNDEZ, 2011/1984, p. 66) e essa consideração é seguida por um delicioso intercâmbio sobre a sorte das perguntas nas práticas educativas entre Antonio e Paulo que transcrevo:

Antonio: No ensino esqueceram-se das perguntas, tanto o professor como o aluno esqueceram-nas, e no meu entender todo conhecimento começa pela pergunta. Começa pelo que você, Paulo, chama de curiosidade. Mas a curiosidade é uma pergunta! Tenho a impressão (e não sei se você concorda comigo) de que hoje o ensino, o saber, é resposta e não pergunta.

PAULO - Exato, concordo contigo inteiramente! E isto que eu chamo de "castração da curiosidade". O que está acontecendo é um movimento unilinear, vai de cá pra lá e acabou, não há volta, e nem sequer há uma demanda; o educador, de modo geral, já traz a resposta sem se lhe terem perguntado nada! 
Ensino, Saúde e Ambiente - v. 14 n. esp. (2021): Dossiê Paulo Freire para além dos 100 anos: construir utopias, transformar a realidade, p. 288-300.

\section{Lutas sociais e educação popular}

A educação esqueceu das perguntas e, sobretudo, da curiosidade que está na base do perguntar. Ou como Faundez afirma: “a curiosidade é uma pergunta!”. É justamente essa curiosidade que a presente escrita não apenas não pretende castrar quanto que fícaria lisonjeada se conseguir alimentar e cuidar. A pergunta (curiosidade) que nos anima é: o que levou a Paulo Freire a se dedicar à alfabetização de jovens e adultos em vez da alfabetização de crianças? Por que, afinal, alguém com uma relação tão extraordinária com a infância (MAFRA; SILVA, 2020), não se ocupou da alfabetização infantil e sim da de jovens e adultos? A curiosidade é algo muito próprio da infância, de modo que discorrer sobre o valor que a curiosidade tem para Paulo Freire pode ser uma boa maneira de começar a pensar em nossa pergunta inicial.

\section{PAULO FREIRE E A CURIOSIDADE}

Para Paulo Freire, a curiosidade tem um valor extraordinário: é o motor das perguntas e, com elas, do pensamento, pois todo pensar começa no perguntar. Trata-se de uma aprendizagem fundamental não apenas para estudantes mas, sobretudo, para educadores: o de não relacionarmo-nos com a pergunta apenas como

um jogo intelectual, mas viver a pergunta, viver a indagação, viver a curiosidade, testemunhá-la ao estudante. O problema que, na verdade se coloca ao professor é o de, na prática, ir criando com os alunos o hábito, como virtude, de perguntar, de “espantar-se". (FREIRE; FAUNDEZ, 2011/ 1984, p. 70).

Viver a pergunta; perguntar-se e não apenas perguntar ou lançar perguntas ao mundo. Deixar-se afetar e atravessar, no próprio pensamento e na própria vida, pelas perguntas que o mundo lança em nós. Viver perguntando-nos. É isso que gostaria de convidar as leitoras e leitores neste breve exercício de escrita: a vivermos o perguntar, espantarmo-nos com a pergunta, viver a curiosidade que sustenta uma pergunta.

No contexto da conversa que estou transcrevendo entre Antonio Faundez e Paulo Freire, o mestre pernambucano conta uma anedota curiosa, significativa, a partir de uma intervenção sua na sua primeira visita à Argentina, em Buenos Aires. Prestes a fazer uma palestra, em vez de oferecer um discurso, Paulo convidou os moradores de um bairro periférico de Buenos Aires a fazerem perguntas. Rapidamente, um dos moradores diz que achava uma ótima ideia e fez o que Paulo Freire chama "a pergunta fundamental": "o que 
Ensino, Saúde e Ambiente - v. 14 n. esp. (2021): Dossiê Paulo Freire para além dos 100 anos:

construir utopias, transformar a realidade, p. 288-300.

\section{Lutas sociais e educação popular}

significa mesmo perguntar?" (FREIRE; FAUNDEZ, 2011/ 1984, p. 70) e mostra como ele tentava manter viva a curiosidade que estava por trás dessa e das outras perguntas que surgiram ("Em lugar de responder sozinho tentei arrancar do grupo o que lhe parecia ser perguntar"). É algo assim que gostaríamos de propor para a nossa pergunta.

A questão da curiosidade é central na vida e na obra de Paulo Freire, e essa centralidade se manifesta de diversas maneiras. Por um lado, ele considera a curiosidade ontológica - o querer "ser mais" - como constitutiva de uma vida humana (FREIRE, 2014), uma vocação que toda prática educativa deveria respeitar, preservar e cultivar. Por outro lado, manter viva a própria curiosidade - que muitas vezes é identificada com a infância ou meninice - é uma condição para os educadores e educadoras de todas as idades, ele mesmo em primeiro lugar.

Não apenas na educação a curiosidade menina é vital. O livro que estamos lendo, em que Paulo e Antonio narram suas errâncias provocadas pelo exílio, termina com um sonoro elogio da revolução sandinista. Paulo relembra a sua primeira visita a Manágua, em novembro de 1979, quando perante um grande grupo de militantes que foram ao seu encontro no Ministério de Educação, compartilhava-lhes a impressão que tinha da revolução sandinista: uma revolução menina! E assim justifica sua impressão:

Menina, não porque recém-“chegada", mas pelas provas que estava dando de sua curiosidade, de sua inquietação, de seu gosto de perguntar, por não temer sonhar, por querer crescer, criar, transformar. Disse também naquela tarde quente que era necessário, imprescindível que o povo nicaragüense, lutando pelo amadurecimento de sua revolução, não permitisse porém que ela envelhecesse, matando em si a menina que estava sendo. Voltei lá recentemente. A menina continua viva, engajada na construção de uma pedagogia da pergunta. (FREIRE; FAUNDEZ, 2017/1985, p. 230-1)

Prestemos atenção: menina não pelo pouco tempo de vida, mas pela forma curiosa e inquieta de viver. Assim, a curiosidade e a inquietação de uma vida menina importam também nada menos que numa revolução, algo tão necessário entre nós. Manter viva uma revolução é manter viva sua curiosidade, sua inquietação, seu perguntar-se o que é e como ser uma revolução que mereça esse nome. A pedagogia da pergunta é a forma educacional de vivermos vidas individuais e coletivas curiosas e inquietas.

A curiosidade é para Paulo Freire um valor educacional inegociável, irrenunciável. Numa entrevista com Nilcéa Lemos Pelandré que o questiona sobre a também muito sensível questão do método, Paulo Freire afirma: 
Ensino, Saúde e Ambiente - v. 14 n. esp. (2021): Dossiê Paulo Freire para além dos 100 anos:

construir utopias, transformar a realidade, p. 288-300.

\section{Lutas sociais e educação popular}

Eu preferiria dizer que não tenho método. O que eu tinha, quando muito jovem, há 30 anos ou 40 anos, não importa o tempo, era a curiosidade de um lado e o compromisso político do outro, em face dos renegados, dos negados, dos proibidos de ler a palavra, relendo o mundo. (PELANDRÉ, 2014, p. 14)

Espero que essa passagem ascenda a curiosidade de quem está lendo porque ela é mesmo muito curiosa e despertadora de curiosidades: sim, Paulo Freire, o criador de um mundialmente badalado método de alfabetização para jovens e adultos, afirma que não tem método, mas o que tem é "curiosidade e compromisso político". O método é o de cada educador, não há um método único para alfabetizar, mas o que não pode faltar em qualquer proposta ou prática educacional é a curiosidade e o compromisso político com as e os excluídos. A curiosidade está no início, é o que move o perguntar e, com ele, toda prática educativa (é o combustível do seu “por quê?”); o compromisso com as excluídas e excluídos é o que lhe oferece sentido (é o alimento do seu "para quê"?). Por que perguntamos e (nos) educamos através de uma pedagogia da pergunta? Porque habitamos curiosa e meninamente o mundo, penso, diria o educador pernambucano. Para que perguntamos e (nos) educamos através de uma pedagogia da pergunta? Para desdobrar nosso compromisso político com os proibidos de ler a palavra, relendo o mundo.

Finalmente, há um outro sentido em que a curiosidade está muito presente na vida e na obra de Paulo Freire: cada vez que ele se conecta com sua própria infância. Por exemplo em Cartas a Cristina, quando afirma algo que aparece também de modo semelhante em outros escritos: "Voltar-me sobre minha infância remota é um ato de curiosidade necessário". (P. Freire, 2015, p. 41). Ou seja, aparece aqui uma dupla curiosidade: a curiosidade de se encontrar com o momento da vida onde nasce a curiosidade. A vida de Paulo Freire é uma vida muito curiosa desde menino. Por que é uma curiosidade necessária retomar a infância? Porque se aprende dela; porque compreendê-la permite entender o próprio Paulo Freire adulto, maduro que, por exemplo, já na infância pensava que o mundo tinha que ser mudado; e também porque, como o destaca em diversos relatos (FREIRE, 2015 2013; FREIRE; GUIMARÃES, 1982), a maneira como ele foi alfabetizado, ainda criança, com palavras do seu mundo infantil, esteve presente em suas ideias sobre a alfabetização e em sua maneira de pensá-la e praticá-la como educador de jovens e adultos. 
Ensino, Saúde e Ambiente - v. 14 n. esp. (2021): Dossiê Paulo Freire para além dos 100 anos:

construir utopias, transformar a realidade, p. 288-300.

Lutas sociais e educação popular

\section{UM MENINO CURIOSO NUM CONGRESSO ADULTO DE LEITURA}

Quero dar atenção a uma conhecida intervenção de Paulo Freire no $3^{\circ}$ Congresso de Leitura em Campinas, em novembro de 1981. Essa intervenção deu lugar a um livro, muito lido, muito citado: A importância do ato de ler. (FREIRE, 2011) Paulo Freire tinha chegado recentemente do exílio; todos e todas queriam ouvi-lo, tocá-lo, senti-lo. Lerei com calma essa intervenção à busca de signos que nos permitam pensar a nossa pergunta. Parece mais do que esperável; afinal, é um congresso de leitura e Paulo Freire se reencontra com educadores de todas as idades que estão muito curiosos para escutar a sua palavra.

O início surpreende. Paulo Freire afirma que raramente se permitiu abrir ou encerrar um Congresso. Não diz por quê. Faria mais sentido, para um menino, não gostar de encerrar eventos. Mas gostar de abri-los pareceria bem próprio de sua presença menina. Esclarece que aceitou fazê-lo da maneira "menos formal possível". Parece mais compreensível essa afirmação inicial para justificar a forma de uma fala mais informal. Um recurso menino, afinal. Faz sentido.

Os primeiros parágrafos são sempre muito marcantes. No caso de "A importância do ato de ler" não é diferente. Depois de alertar sobre o caráter meninamente informal da intervenção vem um parágrafo de princípios. Nele Paulo Freire refere-se a sua preparação para a fala, a sua escrita do texto que ora está lendo. Lembra seus princípios mais caros: a compreensão crítica do ato de ler que não se esgota da decodificação da palavra escrita mas se alonga na inteligência do mundo; a leitura do mundo precede a leitura da palavra; compreender um texto exige perceber as relações entre texto e contexto... e ainda nesse primeiro parágrafo aparece a necessidade de ir até a infância, da retomada das experiências mais remotas: "a retomada da infância distante, buscando a compreensão do meu ato de "ler" o mundo particular em que me movia - e até onde não sou traído pela memória - me é absolutamente significativa.” (FREIRE, 2011, p. 20.

O texto segue com um exercício de memória, pelo Bairro de Casa Amarela em Recife, até chegar naquele momento ainda anterior à leitura da palavra. Paulo Freire enfatiza mais de uma vez a importância de re-criar e re-viver essa experiência mundana infantil. Com algumas árvores o menino Paulo tinha uma intimidade que só se tem com gente. A descrição do seu primeiro mundo é feita com muito carinho e cuidado, em tom literário; ela inclui nomes de pássaros, - sanhaço, olha-pro-caminho-quem-vem, bem-te-vi, sabiá; cores e formas de frutas 
Ensino, Saúde e Ambiente - v. 14 n. esp. (2021): Dossiê Paulo Freire para além dos 100 anos:

construir utopias, transformar a realidade, p. 288-300.

\section{Lutas sociais e educação popular}

que iam mostrando diversos estágios de amadurecimento - e o próprio sentido de verbos como amolegar; os diversos animais que compunham o mundo familiar; o relato é também povoado de certos medos às almas penadas que precisavam da escuridão para aparecer.

Paulo Freire também destaca que sua curiosidade menina de compreender o mundo não fez dele um adulto em miniatura; não fez ele perder a sua meninice, ao tempo em que seus próprios pais iam introduzindo-o no mundo das palavras. Outras lembranças acompanham o relato e chegam até sua primeira vida como professor de língua portuguesa. Surgem também críticas à exigência de muitos professores de leituras mecânicas focadas na quantidade de páginas e não na experiência da leitura, uma crítica ao que Paulo Freire chama de "magicização" da palavra (2011, p. 27).

Finalmente, Paulo Freire destaca que a alfabetização de adultos é um ato político e de conhecimento, por tanto, criador. Nesse mesmo sentido, igualitário. $\mathrm{O}$ alfabetizado não é mais do que o analfabeto. Só pode ler e escrever o que o outro pode sentir, perceber e dizer. Alfabetizar-se, ler e escrever a palavra é um ato de criação em que a leitura do mundo precede sempre à leitura da palavra e esta implica a continuidade daquela. Esse processo provoca a releitura (e reescrita) permanentes da palavra e do mundo: leitura da leitura anterior. Paulo Freire não o menciona aqui, mas a pergunta tem ali também um papel extraordinário como tradutora das inquietações e curiosidades que as novas leituras do mundo trazem em relação à leitura anterior e, dessa forma, como motora do pensamento.

\section{CARTAS DE INFÂNCIA}

Nathercia Lacerda publicou seis cartas que Paulo Freire escreveu para ela nos tempos do exílio em Santiago do Chile, enquanto escrevi a Pedagogia do Oprimido. A obra é linda e muito cuidada (LACERDA, 2016): as seis cartas de Paulo Freire estão datilografadas e fotografadas conforme o manuscrito original e ilustradas com imagens, desenhos e fotos do tempo das cartas. A correspondência começa em 1967, quando ela tinha 9 anos e ele 45 e termina um par de anos depois. Paulo Freire estava nesse tempo em Santiago do Chile e só a última carta já é desde Cambridge, EUA, onde tinha-se mudado recentemente. Transcrevo um trecho da terceira carta:

A cidade está ficando cheia de flores, de tôdas as côres. O jardim da nossa casa azul está com a grama toda verdinha. As roseiras começam a abrir suas rosas. A gente olha para as roseiras e parecem gente rindo. Meninos rindo, com a pureza do riso 
Ensino, Saúde e Ambiente - v. 14 n. esp. (2021): Dossiê Paulo Freire para além dos 100 anos:

construir utopias, transformar a realidade, p. 288-300.

\section{Lutas sociais e educação popular}

das crianças. Se os homens grandes, as pessoas grandes pudessem ou quisessem rir como as roseiras, como as crianças, não lhe parece que o mundo seria uma coisa linda? Mas eu acredito que um dia, com o esforço do próprio homem, o mundo, a vida vão deixar que as pessoas grandes possam rir como as crianças. Mais ainda - e isto é muito importante - vão deixar que todas as crianças possam rir. Porque hoje não são todas as que podem rir. Rir não é só abrir ou entreabrir os lábios e mostrar os dentes. É expressar uma alegria de viver, uma vontade de fazer coisas, de transformar o mundo, de amar o mundo e os homens, somente como se pode amar a Deus (LACERDA, 2016, p. 57-58).

As cores, as flores, o riso. Parece o mundo animado da casa de Recife que relatamos. Já passou a idade cronológica infantil mas a intimidade de Paulo Freire com a natureza mantém-se viva e faz que ela pareça gente: por isso, as rosas riem com pureza, como uma criança. É preciso sorrir como as roseiras para que o mundo seja mais bonito. Paulo Freire faz, nesse trecho, uma pergunta retórica a Nathercinha, uma pergunta que não pergunta mas sugere: você não acha que as pessoas grandes pudessem ou quisessem rir como as roseiras, como as crianças, o mundo seria uma coisa linda? A pergunta parece retórica porque contém ou espera uma resposta afirmativa que ela já sabe: não é uma pergunta para saber mas de alguém que já sabe. Contudo, é uma pergunta que faz pensar e que contém outras perguntas de resposta nada fácil: por que as pessoas grandes não querem rir? Por que elas não podem rir? Por que elas não riem como riem as crianças? É a parte mais dura, mais crítica da carta. E logo depois Paulo parece querer fazer rir a Nathercinha e se mostra confiante, esperançoso.

Há vários aspectos principais que me importa destacar nesta carta. O primeiro é que a infância aparece como um horizonte desejável: são as crianças que riem e os adultos que poderiam habitar o mundo infantilmente; não são as crianças que precisam se transformar em adultos mas os adultos que poderiam se inspirar em certas maneiras infantis de habitar o mundo. $O$ segundo aspecto é que não são todas as crianças que vivem uma vida infantil. O riso é uma marca de infância e nem todas as crianças podem rir. Há, portanto, muitas crianças sem infância. Mas há também muita infância para além das crianças. Um mundo desejado não é apenas aquele em que todos os adultos riam como riem as crianças mas um mundo em que todas as crianças possam rir e não como agora em que só algumas crianças podem fazê-lo. Um terceiro aspecto diz respeito a uma certa esperança que a carta transmite, uma confiança em que, com esforço, esse mundo onde a infância e seu riso sejam um direito de todos os seres humanos será alcançado, é um mundo sonhável. Finalmente, um último aspecto significativo: rir tem várias camadas; há um rir aparente, superficial, figurativo e há também um rir nas profundezas em que rir é uma alegria de viver, uma vontade de fazer coisas, transformar o mundo e amar o mundo e os seres humanos. Rir é mais do que uma aparência no rosto: é uma força da infância, uma potência transformadora do mundo. É preciso que todos os seres humanos, de todas as idades, possam sorrir igual todas as crianças para que o mundo fique mais bonito de verdade, ou seja, mais justo, mais alegre, mais cheio de vida. Há portanto duas transformações que o mundo necessita: que todas as 
Ensino, Saúde e Ambiente - v. 14 n. esp. (2021): Dossiê Paulo Freire para além dos 100 anos: construir utopias, transformar a realidade, p. 288-300.

\section{Lutas sociais e educação popular}

crianças riam - e não só algumas como agora - e que todos os seres humanos riam como riem as crianças. É preciso uma infância do mundo para que todas as vidas sejam vidas de verdade, de alegria, de curiosidade, de amor. O mundo precisa de uma infância para tornar-se um mundo mais mundo para todas as pessoas de todas as idades.

Por isso, é preciso que todos cuidemos de nossa meninice e não deixemos ela morrer. Isso afirma Paulo a Nathercinha já desde a primeira carta:

É uma coisa boa, Natercinha, que a gente nunca deixe de ser menino. Os homens atrapalham as coisas, complicam tudo. Não sei se você vai entender isso que vou lhe dizer. Mamãe e papai lhe explicam melhor. Cresça, mas nunca deixe morrer em você a Natercinha de hoje, que começa a descobrir o mundo, cheia de curiosidade. Se os homens não deixassem morrer dentro deles o menino que eles foram, se compreenderiam melhor. (LACERDA, 2016, p. 50-1)

$\mathrm{Na}$ escrita da primeira parte dessa primeira carta, Paulo Freire tinha relato seu encantamento no seu primeiro encontro com a neve, experiência menina, ainda aos 45 anos: a alegria menina de brincar de boneco de neve. Aproveita para dizer que a meninice ou infância é algo que todos os seres humanos precisamos conservar. A menina é quem "começa a descobrir o mundo, cheia de curiosidade." É isso que precisamos manter viva: a curiosidade na descoberta do mundo. Até nos compreenderíamos melhor, o mestre pernambucano sugere.

Importa-me também destacar algo que como fundo das cartas. Paulo Freire escreve para Natherzinha, como um igual, uma amiga importante à qual precisa se dedicar tempo e cuidado mesmo com todas as ocupações do tempo em que está escrevendo a Pedagogia do Oprimido. Há apenas um trechinho em que Paulo Freire parece se esquecer da infância e fala como "gente grande", quando afirma que o pai e a mãe de Nathercinha poderão lhe "explicar melhor" o que ele está afirmando, pressupondo que há coisas que uma menina não pode entender por si própria. Em qualquer caso, é uma carta de muito cuidado, respeito e amorosidade com a infância.

POR QUE ALFABETIZAR ADULTOS EM VEZ DE ALFABETIZAR CRIANÇAS?

Na seção anterior percebemos a profunda relação de Paulo Freire com a infância, no cuidado e respeito que ela mostra na comunicação com uma criança de nove anos (o que se verifica, também, no mais conhecido epistolário de Cartas a Cristina, [FREIRE, 2015]). 
Ensino, Saúde e Ambiente - v. 14 n. esp. (2021): Dossiê Paulo Freire para além dos 100 anos:

construir utopias, transformar a realidade, p. 288-300.

\section{Lutas sociais e educação popular}

Paulo Freire também manteve uma potente relação com sua própria infância, considerando que visitar ela era necessário para forjar suas ideias sobre alfabetização e também manifestando a importância fundamental de todas as pessoas manterem viva a sua infância sem importar a sua idade. Sendo tão significativa a infância para Paulo Freire, por que ele não se dedicou à alfabetização de crianças e sim de pessoas jovens e adultas?

A leitora e o leitor já sabem que não pretendemos responder terminantemente essa pergunta. Mas também sabem que não pretendemos evitá-la. O que queremos é mantê-la viva, fazer surgir, quem sabe, outros questionamentos. Esperamos que isso provoque esta última seção de nosso texto.

Paulo Freire distinguia duas infâncias: a das idades e a da curiosidade ${ }^{2}$ :

sexagenário, tenho sete anos; sexagenário, eu tenho quinze anos; sexagenário, amo a onda do mar, adoro ver a neve caindo, parece até alienação. Algum companheiro meu de esquerda já estará dizendo: Paulo está irremediavelmente perdido. E eu diria a meu hipotético companheiro de esquerda: Eu estou achado: precisamente porque me perco olhando a neve cair. Sexagenário, eu tenho 25 anos. Sexagenário, eu amo novamente e começo a criar uma vida de novo (FREIRE, 2001, p. 101).

Paulo Freire vivia, ao mesmo tempo, em diversos tempos. Distingamos dois tempos principais: por um lado, a) o tempo do relógio e do calendário, o das instituições educativas, dos programas e cronogramas; por outro, b) o tempo da infância, do brincar e do perguntar; são os tempos que os antigos gregos chamavam de khrónos e aión (KOHAN, 2004). O primeiro é um tempo sem presente, pois é a numeração do movimento e sua ordenação em passado e futuro, o movimento que já passou (passado) e o que ainda está por vir (futuro); nesse tempo, o presente é apenas instante, dobradiça, agora; já o segundo é um tempo sem movimento, puro presente, duração. Como na citação que acabamos de oferecer, Paulo Freire considera o segundo tempo essencial para a vida: trata-se daquele tempo em que uma criança brinca, um artista cria, os amantes amam.

Mia Couto, poeta moçambicano, afirma que é na infância que aprendemos o sentimento do tempo. E na escola? O que acontece com o tempo de infância? O perdemos? Ele fica restrito aos recreios / intervalos? A escola é uma palavra multifacetada: sua etimologia remete a um tempo livre, skholé, próprio do brincar no presente, tempo liberado

\footnotetext{
${ }^{2}$ Sobre Paulo Freire e a infância, véase também o capítulo "Infância” em KOHAN, 2019.
} 
Ensino, Saúde e Ambiente - v. 14 n. esp. (2021): Dossiê Paulo Freire para além dos 100 anos:

construir utopias, transformar a realidade, p. 288-300.

\section{Lutas sociais e educação popular}

das exigências sociais de produtividade. Contudo, no seu andar histórico, a escola como instituição, as instituições escolares têm sido tomadas por um tempo regrado, disciplinado, produtivo. Pode a escola acolher o tempo da infância? Pode a escola cuidar ou recordar o sentimento do tempo que aprendemos na infância? Leiamos essa referência de Mia Couto ao tempo de infância:

A infância não é um tempo, não é uma idade, uma coleção de memórias. A infância é quando ainda não é demasiado tarde. É quando estamos disponíveis para nos surpreendermos, para nos deixarmos encantar. Quase tudo se adquire nesse tempo em que aprendemos o próprio sentimento do Tempo. A verdade é que mantemos uma relação com a criança como se ela fosse uma menoridade, uma falta um estado precário. Mas a infância não é apenas um estágio para a maturidade. É uma janela que, fechada ou aberta, permanece viva dentro de nós (COUTO, 2009, p. 103-104).

A infância não é uma idade é uma forma de estar no tempo, de sentir o tempo: uma disponibilidade para a surpresa; para deixarmo-nos encantar. É precisamente essa janela da infância que os educadores e educadoras de todas as idades precisamos manter aberta: ao encantamento, à surpresa. Paulo Freire chamava essa janela de curiosidade e preocupou-se de mantê-la sempre aberta dentro de si. Também alertou sobre a importância de qualquer ser humano manter essa janela aberta dentro de si a qualquer idade.

"A infância é quando ainda não é demasiado tarde", diz o poeta. E a janela da infância permanece viva, aberta ou fechada, dentro de cada ser humano. A frase ecoa fortemente em nossa pergunta. Recordemos o movimento do presente texto. Partimos da importância singular que tem a curiosidade numa vida educadora, da forte relação de Paulo Freire com a infância e do lugar singular que a curiosidade e o compromisso político revistem na vida do neste ano centenário educador de Pernambuco.

Descobrimos, pela janela da infância, uma janela para pensar a nossa pergunta. Há demasiadas crianças e adultos entre nós que não têm motivos para sorrir. E que além de terem seus direitos negados têm seu tempo de infância proibido. Vidas negadas, renegadas que resistem à política de extermínio que vêm sendo praticada sobre elas. Vidas com seus direitos roubados e, dentre eles, o seu direito à infância. Vidas que escutam persistentemente - e assim passam a acreditar - que já é tarde demais para ler a palavra. Se esse roubo de infância é cruel com as crianças porque lhes impede de viver uma vida infantil, é ainda mais desumano com os adultos porque os afasta cada vez mais do que poderia ser uma condição para transformar suas próprias vidas. Quanto mais cronologicamente afastados da infância mais forte o tamanho do 
Ensino, Saúde e Ambiente - v. 14 n. esp. (2021): Dossiê Paulo Freire para além dos 100 anos: construir utopias, transformar a realidade, p. 288-300.

\section{Lutas sociais e educação popular}

roubo e mais necessário e desafiador o trabalho educacional de recuperar a infância, de sentir, contra todos os discursos que a negam, que ainda não é demasiado tarde. Que essa janela, fechada, pode ser reaberta. Nunca é demasiado tarde, parecia pensar Paulo Freire, tal sem compromisso com a infância. Paulo Freire amava as crianças, mas talvez amava mais ainda a infância sem idade, essa curiosidade que está na base de toda pergunta e, assim, de toda transformação. Essa janela que todos temos e é necessário manter aberta. Talvez por isso, dedicou-se à alfabetização das pessoas que já estão longe da infância cronológica e precisavam de um menino conectivo e conjuntivo para lembrar que, em qualquer momento da vida, nunca é tarde para ler a palavra, reler o mundo, e sonhar com outros mundos.

\section{REFERÊNCIAS}

COUTO, Mia. E se Obama fosse africano? e outras interinvenções. Ensaios. São Paulo: Companhia das Letras, 2009.

FREIRE, Paulo. A importância do ato de ler. Em três artigos que se complementam. São Paulo: Cortez, 2011.

FREIRE, Paulo. À sombra desta mangueira. Organização e notas de Ana Maria Araújo Freire. Rio de Janeiro: Paz e Terra, 11 Ed., 2013.

FREIRE, Paulo. Pedagogia da Esperança. Um reencontro com a Pedagogia do Oprimido. São Paulo: Paz e Terra, 2014.

FREIRE, Paulo. Cartas a Cristina. Reflexões sobre minha vida e minha práxis. São Paulo Paz e Terra, 2a ed., 2015.

FREIRE; Paulo; FAUNDEZ, Antonio. Por uma pedagogia da pergunta. São Paulo: Paz e Terra, 2011.

FREIRE, Paulo; GUIMARÃES, Sérgio. (1982). Sobre educação: diálogos. Rio de Janeiro: Paz e Terra, 1982.

KOHAN, Walter Omar. A infância da educação: o conceito devir-criança. In: Lugares da infância: filosofia. Rio de Janeiro: DP\&A, 2004, p. 51-68.

KOHAN, Walter Omar. Paulo Freire mais do que nunca: uma biografia filosófica. Belo Horizonte: Vestdígio, 2019.

SILVA, Marta Regina Paulo da; MAFRA, Jason Ferreira (orgs.). Paulo Freire e a educação das crianças. São Paulo, BT Acadêmica, 2020.

PELANDRÉ, Nilcéa Lemos . Entrevista com Paulo Freire, EJA EM DEBATE, Florianópolis, a. 3, n. 4, p. 13-27, jul. 2014. Entrevista publicada inicialmente em: PELANDRÉ, N. L.

Ensinar e Aprender com Paulo Freire: 40 horas 40 anos depois. 3. ed. rev. Florianópolis: 
Ensino, Saúde e Ambiente - v. 14 n. esp. (2021): Dossiê Paulo Freire para além dos 100 anos: construir utopias, transformar a realidade, p. 288-300.

\section{Lutas sociais e educação popular}

Editora da UFSC, 2009.

\section{SOBRE O AUTOR}

Walter Omar Kohan é pós-doutor em filosofia pelas Universidades de Paris 8 e British Columbia (Canadá). Professor titular da UERJ, foi presidente do Conselho para a Investigação Filosófica com Crianças (ICPIC). Autor ou organizador de mais de cinquenta livros, dentre eles: O mestre inventor (Autêntica, 2014); Manifesto por uma escola filosófica popular (filoeduc.org/editora) e Paulo Freire mais do que nunca. Uma biografia filosófica (Vestígio, 2019). 